04

\title{
Метод персонализации фотополимерных защитных голограмм на основе записи скрытых кодированных цифровых изображений
}

\author{
() С.Б. Одиноков ${ }^{1}$, В.В. Колючкин ${ }^{19}$, Д.В. Кузьмин ${ }^{1}$, В.Е. Талалаев ${ }^{1}$, П.А. Ханевич ${ }^{1}$, А.В. Смирнов ${ }^{2}$, \\ Л.И. Смирнов ${ }^{2}$ \\ ${ }^{1}$ Московский государственный технический университет им. Н.Э. Баумана, \\ 105005 Москва, Россия \\ ${ }^{2} \mathrm{AO}$ „НПО „Криптен“, \\ 141980 Дубна, Московская обл., Россия \\ ฯ e-mail: vkolyuchkin@bmstu.ru
}

Поступила в редакцию 16.12.2020 г.

В окончательной редакции 16.12.2020 г.

Принята к публикации 22.12.2020 г.

Рассмотрена проблематика встраивания персональных данных при тиражировании защитных голограмм на фотополимерной основе с максимальным сохранением площади голограммы при ее визуализации. Предложен метод записи на фотополимерный носитель персонализированных защитных голограмм, содержащих помимо основной голограммы с визуальным изображением дополнительную компьютерно-синтезированную микроголограмму Фурье с индивидуальными данными. Приведен алгоритм синтеза и представлена техническая реализация метода записи микроголограмм Фурье. Проведены экспериментальные исследования по записи и считыванию персонализирующих микроголограмм Фурье, подтвердившие работоспособность предложенного метода.

Ключевые слова: фотополимерная защитная голограмма, персонализация, цифровые кодированные изображения, компьютерно-синтезированная голограмма Фурье, микроголограмма.

DOI: $10.21883 /$ OS.2021.04.50765.299-20

\section{Введение}

Защита документов от подделки является одной из серьезных проблем безопасности, стоящих перед мировой экономикой и государственными организациями разных стран. Например, мероприятия по идентификации и аутентификации паспортов на контрольно-пропускных пунктах входят в комплекс мер по обеспечению охраны периметра важных государственных объектов. Для защиты от подделок в России приняты соответствующие правила [1] по использованию в обязательном порядке защитных голограмм (ЗГ) на идентификационных документах (паспортах, пропусках), банковских пластиковых карточках, векселях и акциях, акцизных марках, лекарственных препаратах и др.

Современное развитие технологий в защищенной голографии предусматривает использование персонализированных данных: для системы учета и контроля носителей голограмм [2] используют сквозную нумерацию и кодирование. В последние годы персонализация ЗГ развивалась по направлению нанесения на поверхность пленочного носителя серийной цифровой нумерации или стандартного штрих-кода, например, с помощью лазерных и термотрансферных принтеров. Однако такой метод персонализации каждой отдельной защитной голограммы имеет недостатки. Во-первых, цифры и штрихи „затеняют“ восстанавливаемое с голограммы изображение из-за размеров наносимых знаков, что в большей степени сказывается на визуализации 3D-изображения.
Во-вторых, напечатанные индивидуальные номера располагаются на поверхности голограммы и могут быть преднамеренно или случайно стерты либо переделаны, что практически невозможно предотвратить. Формирование скрытых голограммных оптических элементов не имеет описанных полиграфических ограничений, но при использовании стандартной технологии массового тиражирования персонализация каждой отдельной защитной голограммы невозможна. Связано это с тем, что в машинах рольного типа используется мастерматрица, содержащая фиксированные голографические изображения единого дизайна, и скрытые голографические изображения получаются одинаковыми на всю партию 3Г.

В настоящее время наиболее востребованными становятся защитные голограммы, получаемые на фотополимерном материале [3], так как они позволяют восстанавливать легко наблюдаемые цветные 3D-изображения со значительной глубиной, а также эффектами динамики, переключения и др. Получение многоцветных объемных мастер-голограмм на пленочном фотополимерном носителе обеспечивается путем голографической записи с помощью опорного и предметного пучков когерентного излучения с использованием RGB-лазеров. Тиражирование фотополимерных многоцветных голограмм производится путем записи интерференционной картины методом контактного копирования с мастер-голограммы, закрепленной на вращающемся валу. Но при такой 
технологии тиражирования все голограммы-копии в серии, записанные с единой мастер-голограммы, также получаются идентичными друг другу и не содержат индивидуального персонализирующего элемента.

Настоящая работа посвящена описанию метода и технической реализации персонализации фотополимерных защитных голограмм. Предложенный метод заключается в записи в небольшой области фотополимерного материала дополнительной микроголограммы, содержащей скрытое кодированное изображение с индивидуальными данными. Записываемые персонализирующие микроголограммы обеспечивают функционал, необходимый для учета документов и товарооборота, и при этом остаются практически незаметными для наблюдателя за счет особенностей представления данных в виде скрытого кодированного микроизображения. Таким образом, повышение уровня безопасности документов может быть обеспечено за счет персонализации защитных голограмм на фотополимерных носителях.

\section{Описание метода персонализации фотополимерных защитных голограмм}

Новизна предложенного метода состоит в том, что в фотополимерной защитной голограмме формируется двухуровневая система записи голограмм, включающая голограмму 1-го уровня, восстанавливающую визуальное (видимое глазом) голографическое изображение, и дополнительную микроголограмму 2-го уровня, содержащую скрытое (невидимое глазом) изображение с персональным цифровым кодом для каждой индивидуальной защитной голограммы. Использование пленочных фотополимерных материалов позволяет организовать серийное изготовление таких ЗГ конвейерным способом. Для осуществления технологии персонализации защитных голограмм предложено в плоскости пленочного фотополимера регистрировать дополнительную микроголограмму Фурье (МГФ) методом проекционной записи компьютерно-синтезированной голограммы Фурье (КСГФ) [4], которая, в свою очередь, содержит изображения с индивидуальным цифровым кодом. Считывание таких МГФ и декодирование восстановленной с нее информации реализуется с помощью автоматической или автоматизированной оптико-электронной системы. Микроголограммы Фурье позволяют при малой занимаемой площади порядка $2 \times 2 \mathrm{~mm}^{2}$ обеспечить достаточную для задачи персонализации информационную емкость до 1 Mbit цифровой информации (тексты, графическая информация, звук и др.) и могут быть легко интегрированы в общий дизайн защитного элемента. Записываемая персональная информация может представлять собой изменяемый по инкременту $i_{+1}$ серийный номер для каждой отдельной ЗГ, информацию о производителе, логотипы, правила пользования лекарственными препаратами и др. С такой микроголограммы Фурье может быть восстановлено кодированное изображение, регистрируемое фотоприемным устройством с последующим декодированием входной цифровой информации и ее автоматической идентификацией в виде персональной цифровой информации. Озвученные особенности позволяют значительно повысить степень защищенности голограмм и сделать каждую из них индивидуальной для своей серии.

Метод записи МГФ со скрытыми кодированными изображениями можно условно разделить на несколько этапов. На первом этапе с помощью математических алгоритмов входная цифровая информация кодируется со сжатием в реальном времени и превращается в кодированное изображение, представляющее собой многоразрядный, например, 256-ти бинарный код (рис. 1). Кодирование служит для сжатия записываемой полезной информации, позволяя разместить в одной МГФ персональную цифровую информацию практически любой сложности и добиться стабильного машиночитаемого восстановления определенного количества объема данных. Для составления кодированного изображения использовался алгоритм кодирования из международного стандарта ECMА-378 [5], используемый для записи голографических дисков памяти. Также был применен корректирующий код Рида-Соломона, добавляющий избыточность в данные, что позволяет при последующем считывании и декодировании исправить поврежденные пикселы кодированного изображения и восстановить данные в полном объеме. С помощью алгоритма быстрого преобразования Фурье (БПФ) полученное кодированное изображение преобразуется компьютерно-синтезированную голограмму Фурье (КСГФ). Такое представление информации применяется для скрытия кодированных данных от наблюдателя голограммы. Иными словами, убираются семантические признаки, и человек может увидеть среди элементов дизайна голограммы лишь зону с квазислучайным шумовым распределением.

На следующем этапе КСГФ с помощью жидкокристаллического пространственно-временного модулятора света (ПВМС, SLM) воспроизводится в оптическом виде и вводится в специализированную оптическую систему записи проекционного типа [6-8], в которой с необходимым уменьшением, примерно в 10-20 раз, проецируется на фотополимерный материал. Предварительные расчеты показывают, что если период структуры КСГФ на ПВМС составляет обычно 40-60 $\mu \mathrm{m}$, то при уменьшении в 20 раз на фотополимерном материале формируется оптическая микроголограмма Фурье с периодом структуры около $3 \mu \mathrm{m}$, т.е. структура с пространственными частотами порядка $350 \mathrm{~mm}^{-1}$. Таким образом, выполняется оптическая запись МГФ обычно с линейными размерами от 0.5 до $2 \mathrm{~mm}$ в требуемом локальном месте на фотополимерном материале, куда затем будет записана основная защитная голограмма методом контактного оптического копирования.

Заключительным этапом записи персонализирующей микроголограммы является непосредственная регистра- 


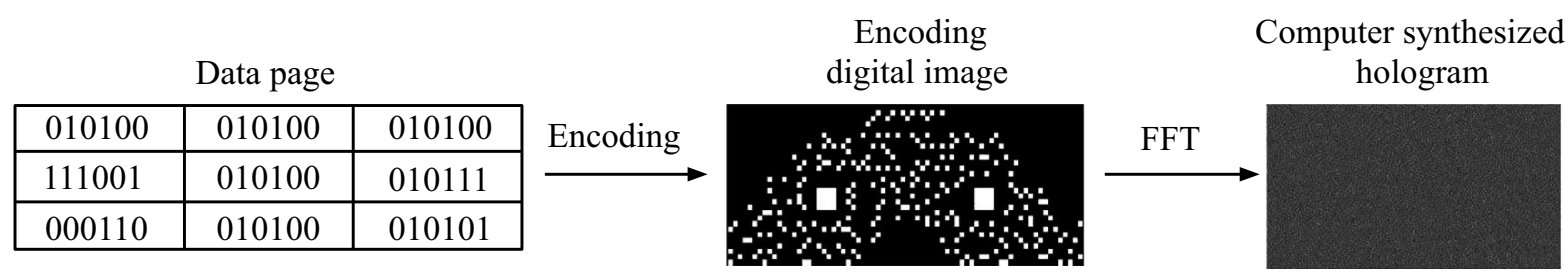

Pис. 1. Схема алгоритма кодирования цифровой информации и формирования компьютерно-синтезированных голограмм Фурье.

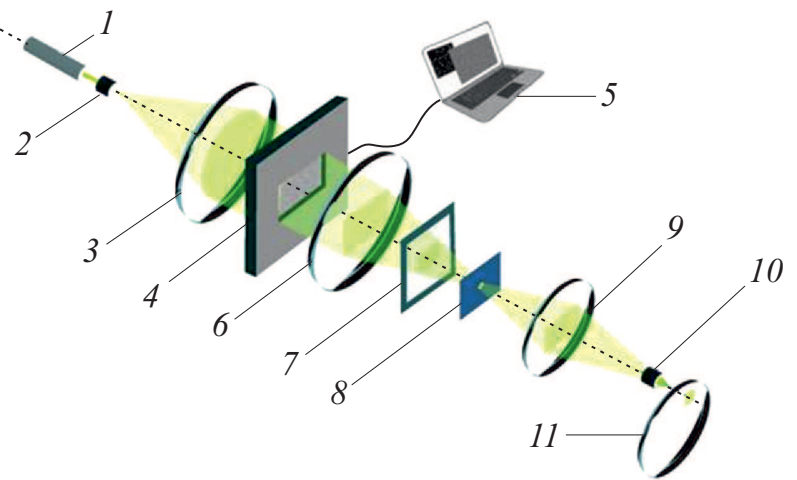

Рис. 2. Схема проекционной записи МГФ на фотополимерный носитель. 1 - светодиод, 2 - микрообъектив, 3 - объектив, 4 - ПВМС, 5 - компьютер, 6 - фурье-объектив, 7 - анализатор, 8 - диафрагма, 9 - объектив, 10 - микрообъектив, 11 - фотополимерный носитель.

ция изображения выводимой на ПВМС компьютерносинтезированной голограммы Фурье на фотополимерном материале. На рис. 2 представлена схема проекционной записи МГФ некогерентным излучением. Схема состоит из источника излучения, коллимирующей системы, необходимой для формирования параллельного светового пучка, равномерно освещающего апертуру ПВМС, проекционной системы записи, состоящей из длиннофокусного объектива и микрообъектива, а также пространственного фильтра, выполняющего фильтрацию. В качестве источника излучения использован светодиод, работающий в зеленой области спектра, в которой чувствительность фотополимерного материала выше.

При тиражировании защитных голограмм процесс экспонирования МГФ в системе записи может проводиться в старт-стопном режиме работы, причем синхронизированном с электронно-механической частью, отвечающей за линейное перемещение пленочного фотополимерного материала. При этом на фотополимерном материале не могут быть предварительно экспонированы защитные голограммы, поскольку это приведет к полимеризации фотополимерного носителя по всей площади ЗГ, в результате чего концентрации остаточного мономера не хватит для записи достаточно контрастного изображения микроголограммы Фурье. Поэтому сначала производится запись МГФ в соответствии с топологией расположения основных голограмм на фотополимерной ленте, а затем поверх МГФ осуществляется запись ЗГ методом оптического копирования. За время стартстопного перемещения фотополимерной ленты производится расчет новой КСГФ с новыми персонализированными данными для $i_{+1}$ микроголограммы Фурье и ее ввод через ПВМС в оптическую проекционную систему. Далее $i_{+1}$ МГФ экспонируется методом проекции на фотополимерный носитель, и процесс повторяется. Таким образом, запись производится в виде конвейера, при этом каждая микроголограмма Фурье содержит персональную информацию для каждой отдельной защитной голограммы.

Считывание скрытых кодированных изображений может осуществляться проекционным методом в обратном ходе, т.е. путем регистрации фотоприемным устройством увеличенного изображения микроголограммы Фурье с последующим цифровым декодированием и восстановлением записанных данных. Технически для регистрации микроизображений можно использовать лабораторный микроскоп либо более компактное устройство с оптической схемой, аналогичной микроскопу.

\section{Апробация метода записи персонализирующих микроголограмм Фурье}

Для проверки технической реализуемости метода проекционной записи на пленочном фотополимерном материале микроголограмм Фурье с персонализирующими данными был собран лабораторный стенд. Оптическая схема стенда записи (рис. 3) представляет собой проекционную схему, формирующую в плоскости регистрации уменьшенное до заданного масштаба изображение голограммы. В качестве проецируемого изображения выступает компьютерно-синтезированная голограмма Фурье, выводимая на пространственно-временной модулятор света на основе жидких кристаллов. Оптическая схема состоит из одноплощадочного светодиодного источника излучения, проекционной системы, состоящей из длиннофокусного объектива и установленного в обратном ходе лучей микрообъектива с фокусным расстоянием, обеспечивающим необходимый масштаб МГФ в плоскости регистрации на фотополимерном материале, а также пропускающего ПВМС, установленного за первым объективом и освещаемого сходящимся пучком лучей. 


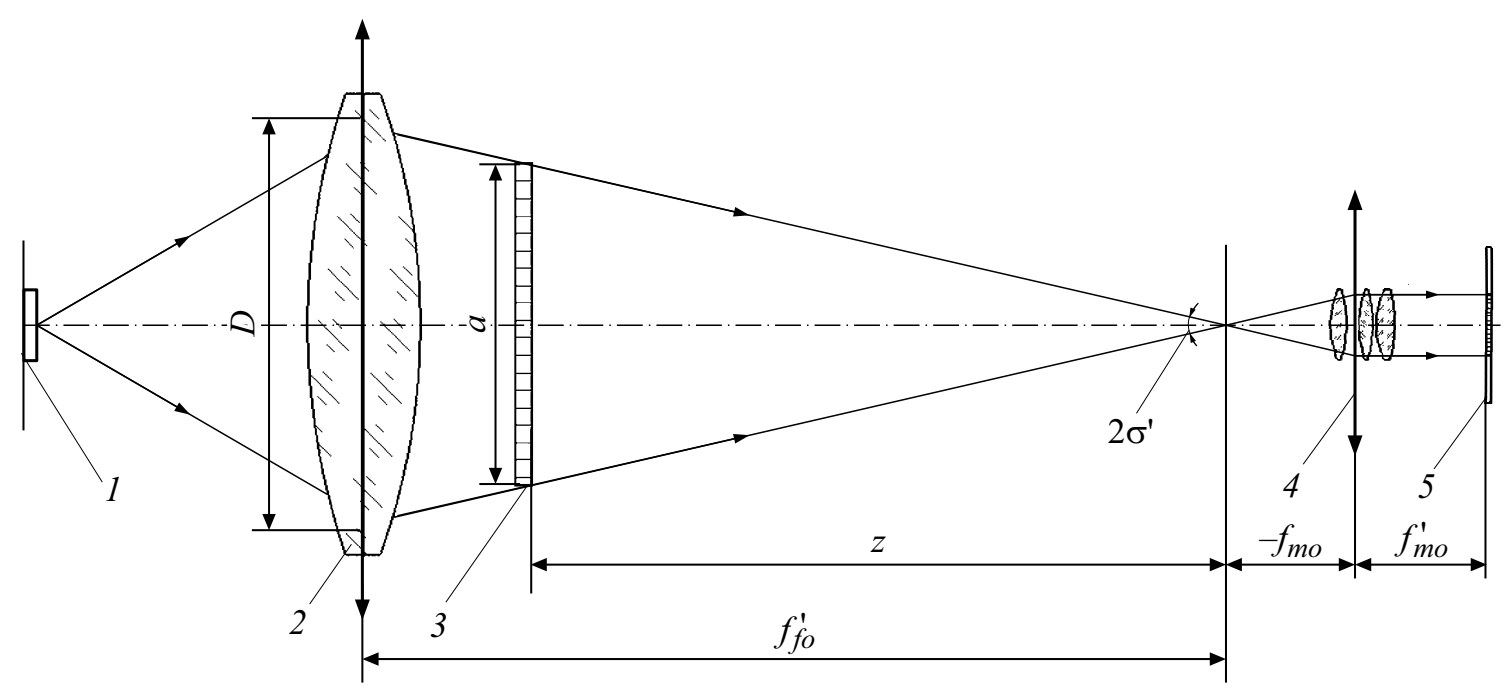

Рис. 3. Оптическая схема стенда записи МГФ: 1 - светодиод, 2 - объектив, 3 - ПВМС, 4 - микрообъектив, 5 - фотополимер.

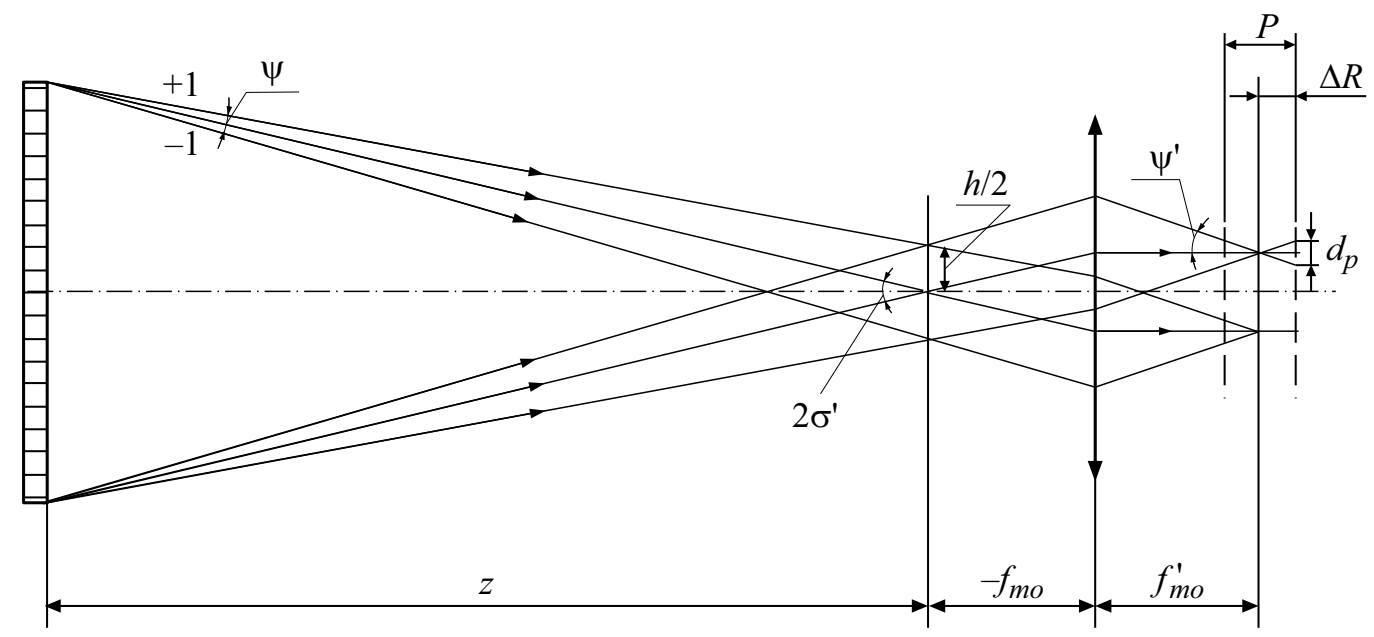

Рис. 4. Оптическая схема для расчета ГРИП.
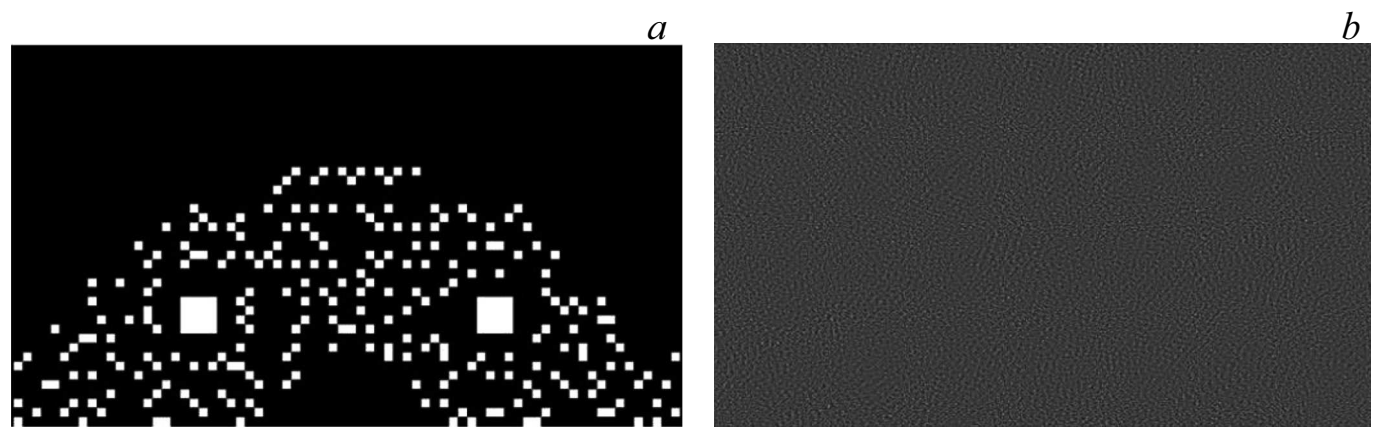

Рис. 5. Преобразованные исходные данные: $a-$ кодированное изображение, $b-$ компьютерно-синтезированная голограмма Фурье.

Для уменьшения габаритов оптической системы первый объектив установлен перед модулятором и выполняет одновременно роль формирователя сходящегося пучка лучей в составе осветительной системы.
В реализованной схеме излучение светодиода с длиной волны $525 \mathrm{~nm}$ освещает пространственновременной модулятор света сходящимся световым пучком и переносит изображение на фотополимер с 


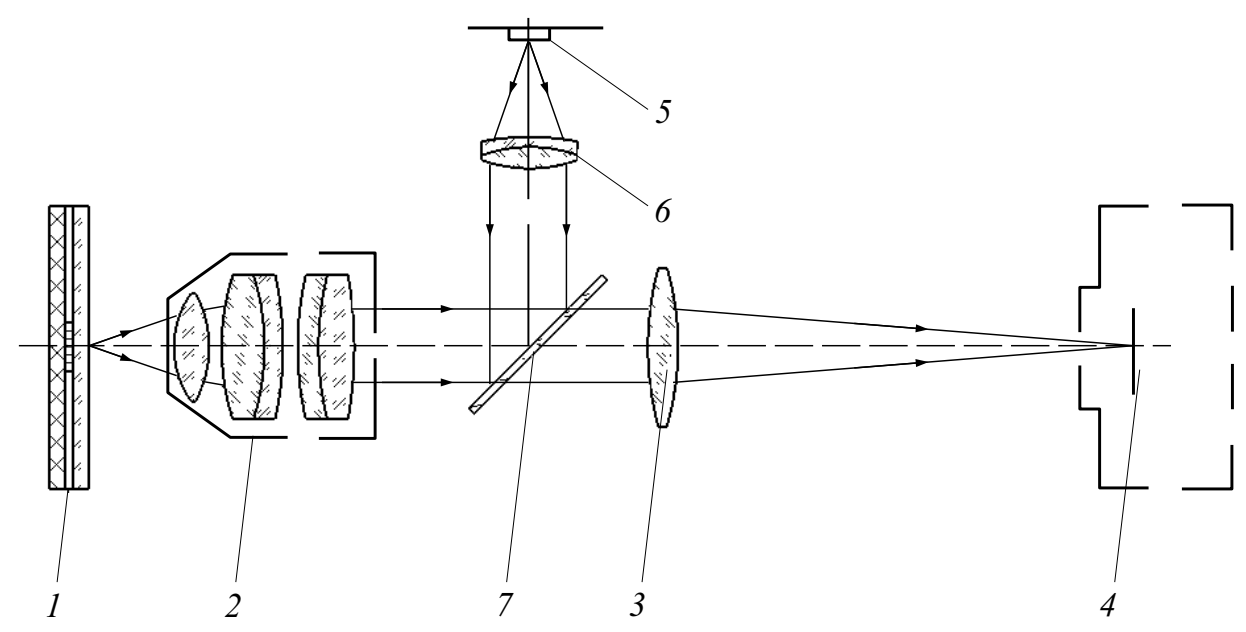

Рис. 6. Оптическая схема макета устройства считывания МГФ. 1 - МГФ, 2 - микрообъектив, 3 - собирающая тубусная линза, 4 - МПИ, 5 - светодиод, 6 - коллимирующий объектив, 7 - стеклянная пластина.

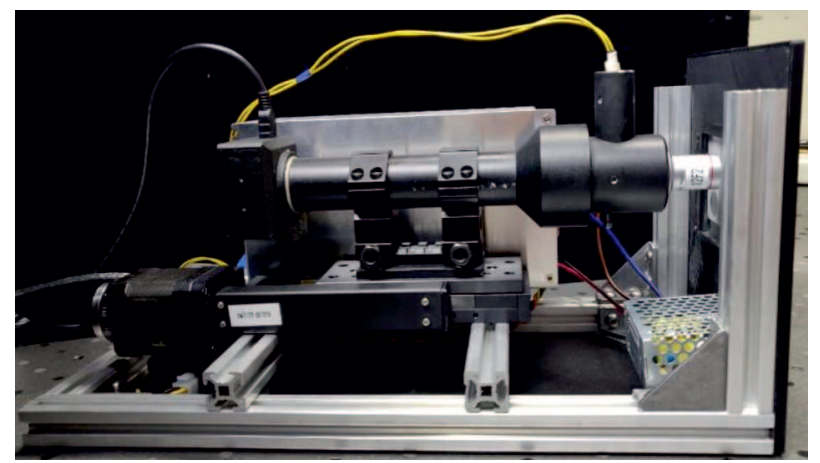

Рис. 7. Макет устройства считывания.

уменьшением в 20 раз. Размерность ПВМС составляет $1024 \times 768$ элементов. Микрообъектив, установленный в стенде записи, имеет увеличение $10^{\times}$и числовую апертуру 0.25 . При этом разрешающая способность записанных микроголограмм составляет около $300 \mathrm{~mm}^{-1}$.

Поскольку в технологическом процессе тиражирования защитных голограмм используются различные подвижные механизмы, целесообразно было провести оценку чувствительности проекционной схемы записи к возможным вибрациям. В качестве критерия оценки была взята глубина резко изображаемого пространства. Данная величина определяется исходя из максимально допустимого значения дифракционного пятна рассеяния в плоскости изображения оптической системы. На рис. 4 показан ход лучей дифрагированной на элементах ПВМС сходящейся волны.

Дифракционный предел разрешения микрообъектива выражается следующим образом:

$$
d=\frac{\lambda}{2 A}
$$

где $A-$ числовая апертура микрообъектива.
Для микрообъектива с числовой апертурой $A=0.25$ дифракционный предел составляет $d=1.05 \mu \mathrm{m}$.

При допущении, что пространственный модулятор света освещается плоской волной, угол дифракции на его элементе можно вычислить по формуле

$$
\psi \approx \sin \psi=\frac{\lambda}{a_{e l}},
$$

тогда размер дифракционного распределения в задней фокальной плоскости фурье-объектива при периоде следования элементов ПВМС $T_{s l m}=38 \mu \mathrm{m}$ и рабочем отрезке $z=560 \mathrm{~mm}$ равен

$$
h \approx \psi z=\frac{\lambda}{a_{e l}} z \approx 7.8 \mathrm{~mm} .
$$

Угол дифракции в плоскости изображения можно выразить как

$$
\psi^{\prime} \approx \operatorname{tg} \psi^{\prime}=\frac{h}{2 f_{m o}^{\prime}} \approx 0.475 .
$$

Дистанцию $\Delta R$ от плоскости фокусировки до границы резко изображаемого пространства можно выразить через допустимое значение пятна рассеяния $d_{s}$, которое примем равным размеру элемента ПВМС в плоскости изображения

$$
\Delta R=\frac{d_{s}}{2 \operatorname{tg} \psi^{\prime}}=\frac{a_{e l} \beta}{2 \operatorname{tg} \psi^{\prime}} \approx 1.9 \mu \mathrm{m} .
$$

Тогда глубина резко изображаемого пространства равна

$$
P=2 \Delta R=3.8 \mu \mathrm{m}
$$

что свидетельствует о достаточно высокой чувствительности проекционной схемы записи МГФ к возможным вибрациям. Необходимо учитывать данную особенность при встраивании устройства записи персонализирующих 


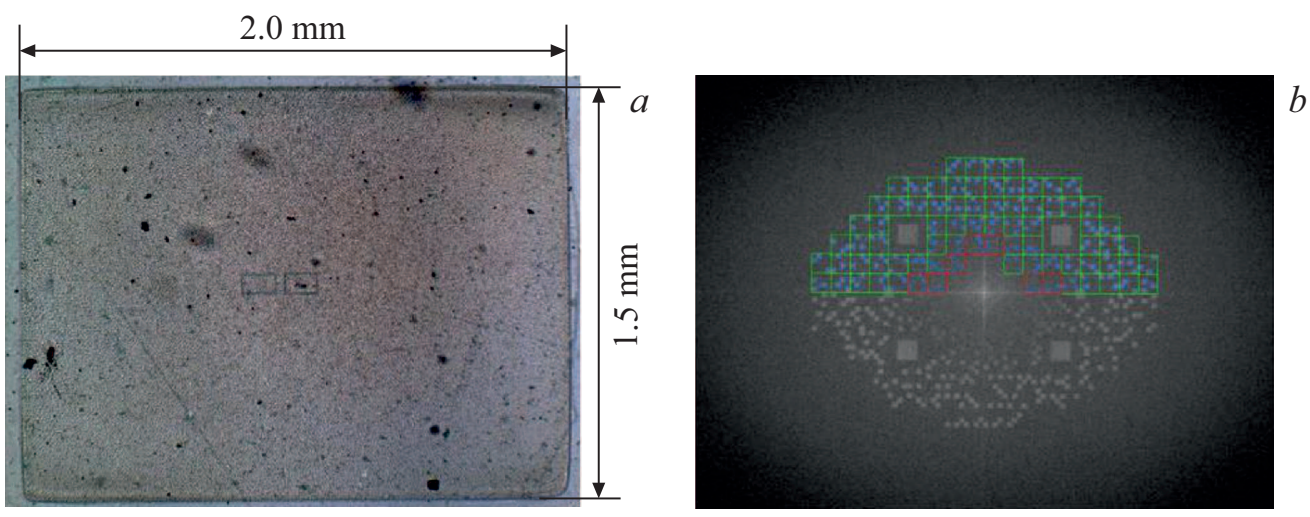

Рис. 8. Считанные данные: $a-$ изображение МГФ, $b-$ восстановленное кодированное изображение.

микроголограмм в технологическую линию тиражирования. Техническим решением, позволяющим выполнить озвученное ограничение, может быть система автофокусировки, встроенная в схему записи МГФ.

Для экспериментальной проверки метода записи в качестве полезных данных, подлежащих записи на фотополимерный материал, была взята текстовая строка „KRYPTEN AB12345678“. С учетом внесенной избыточности с применением корректирующего кода РидаСоломона входные данные были преобразованы в 78 В. При кодировании в нашем случае одному байту в странице данных соответствует изображение размером $32 \times 32$ элемента ПВМС. Сгенерированная страница данных имеет размерность 79872 элемента и соответствует половине площади ПВМС. Для получения равномерной по освещенности синтезируемой голограммы к сгенерированной странице данных добавляется псевдослучайная фазовая маска.

Таким образом, преобразованные данные представляют собой кодированное изображение, которое, в свою очередь, преобразуется в компьютерно-синтезированную голограмму Фурье. Кодированное изображение (рис. 5,a) после применения к нему операции быстрого преобразования Фурье представляет собой КСГФ (рис. $5, b)$, которая выводится на ПВМС и проекционным способом переносится с определенным масштабом на фотополимер.

\section{Проведение эксперимента по считыванию и декодированию МГФ}

Для считывания кодированного изображения с микроголограммы Фурье может быть использовано два известных подхода. Первый основан на использовании некогерентного излучения и оптической проекционной системы для регистрации МПИ изображения МГФ с заданным линейным увеличением с последующим цифровым восстановлением кодированного изображения при использовании алгоритма обратного БПФ. Второй способ [9] основан на освещении МГФ когерентным лазерным излучением с использованием объектива, осуществляющего преобразование Фурье над МГФ, и матричного приемника, регистрирующего восстановленное кодированное изображение. При подсветке когерентным излучением пропускающей микроголограммы, наносимой на отражающую или рассеивающую подложку, в восстановленном фурье-объективом изображении кодированного изображения будет присутствовать значительный уровень спекл-шума от голограммы и подложки. Поэтому предпочтение было отдано проекционному методу считывания МГФ при ее подсветке некогерентным излучением.

Для считывания микроголограмм Фурье с пленочного фотополимерного материала был разработан макет компактного устройства, позволяющий регистрировать проекционным способом изображения таких голограмм. Оптическая схема (рис. 6) проекционного построения увеличенного изображения микроголограммы Фурье состоит из микрообъектива, скорригированного на бесконечность, собирающей тубусной линзы и матричного приемника излучения (МПИ). Микроголограмма, записанная на фоточувствительном материале, подсвечивается пучком некогерентного света, формируемым светодиодом с коллимирующим объективом. Для направления пучка света на МГФ через микрообъектив использована стеклянная плоскопараллельная пластинка. Фотография макета устройства считывания со снятым кожухом представлена на рис. 7.

С помощью созданного макета устройства считывания было зарегистрировано изображение микроголограммы Фурье с размерами $2 \times 1.5 \mathrm{~mm}^{2}$ (рис. $8, a$ ). К данному изображению была применена операция обратного БПФ и получено соответствующее кодированное изображение (рис. 8, $b$ ) с некоторыми искажениями по отношению к исходному. Искажения неизбежно появляются на этапах записи и считывания. Они складываются из линейных искажений оптических проекционных систем, имеющих некоторые аберрации, неравномерности пучка подсветки при считывании, а также экспозиционных особенностей фотополимерного материала. 
На рис. 8, $b$ представлено восстановленное кодированное изображение, дискретные фрагменты (пиксели) которого выделены зеленым или красным цветом. Зеленому цвету соответствуют правильно восстановленные пиксели кодированного изображения, а красному восстановленные неверно. При этом ошибочных ситуаций может быть две - либо восстановленные пиксели находятся в кодирующем алфавите, но не соответствуют исходному кодированному изображению, либо таких восстановленных пикселей в алфавите не существует. Тем не менее за счет внесения избыточности при кодировании исходных данных с использованием кода РидаСоломона в ситуациях, когда корректно идентифицировано более 70\% площади кодированного изображения, кодированное изображение исправляется, и все данные удается восстановить без потерь.

\section{Заключение}

Персонализация позволяет повысить степень защищенности голограмм и сделать каждую из них индивидуальной для своей серии. Предложенное в настоящей работе оригинальное решение по персонализации фотополимерных защитных голограмм позволяет значительно повысить информационную емкость при малой отводимой под персонализацию площади и обеспечить стойкость к стиранию или изменению индивидуальных данных. Проведенные экспериментальные исследования по проекционной записи и считыванию микроголограмм подтвердили реализуемость предложенного метода.

\section{Благодарности}

Работа выполнена в рамках НИР по заказу АО „НПО „Криптен“.

\section{Конфликт интересов}

Авторы заявляют, что у них нет конфликта интересов.

\section{Список литературы}

[1] Федеральный закон „О персональных данных“ от 27.07.2006 N 152-Ф3. Электронный ресурс. Режим доступа http://base.garant.ru/12148567/ (дата обращения 02.11.2020)

[2] Odinokov S., Tsyganov I., Talalaev V., Piryutin N., Kolyuchkin V., Zlokazov E. // Photonics. 2016. V. 55. N 1. P. 84-89.

[3] Trentler T., Ihas B., Cole M., Askham F., Schnoes M., Quirin S., Michaels D., Carter J., Wilson W., Hill A., Stanhope C., Dhar L. // Proc. SPIE. 2004. V. 5380. P. 439. doi 10.1117/12.568042

[4] Betin A.Yu., Bobrinev V.I., Odinokov S.B., Evtikhiev N.N., Starikov R.S., Starikov S.N., Zlokazov E.Yu. // Appl. Opt. 2013. V. 52. N 33. P. 8142-8145. doi 10.1364/AO.52.008142

[5] Standard ECMA-378 Information Interchange on Read-Only Memory Holographic Versatile Disc (HVD-ROM) Capacity: 100 Gbytes per disk. Электронный ресурс. Режим доступа https://www.ecma-international.org/publications/standards/ Ecma378.html (дата обращения 20.05.2020)

[6] Betin A.Yu., Bobrinev V.I., Donchenko S.S., Odinokov S.B., Evtikhiev N.N., Starikov R.S., Starikov S.N., Zlokazov E.Yu. // Appl. Opt. 2014. V. 53. N 28. P. 6591-6597. doi 10.1364/AO.53.006591

[7] Zlokazov E.Yu., Odinokov S.B., Verenikina N.M., Donchenko S.S. // Chinese Opt. Lett. 2017. V. 15. N 4. P. 10.

[8] Betin A.Y., Bobrinyov V.I., Evtikhiev N.N., Zherdev A.Y., Zlokazov E.Y., Lushnikov D.S., Markin V.V., Odinokov S.B., Starikov S.N., Starikov R.S. // Quant. Electron. 2013. V. 43. N 1. P. 87-89.

[9] Odinokov S., Zlokazov E., Donchenko S., Verenikina N. // Jap. J. Appl. Phys. 2017. V. 56. N 9. P. 09NA02. 